\title{
Ocean color observations of eddies during the summer in the Gulf of California
}

\author{
W. Scott Pegau, Emmanuel Boss, and Antonio Martínez \\ College of Oceanic and Atmospheric Sciences, Oregon State University, Corvallis, Oregon, USA \\ Received 14 September 2001; accepted 28 December 2001; published 4 May 2002.
}

[1] Using SeaWiFS ocean color satellite images collected during 1997-2001, a series of eddies have been observed in the Gulf of California. These eddies are not clearly seen in the summertime sea surface temperature images. The surface circulation between the midriff islands and the mouth of the gulf appears to be dominated by this series of eddies that have an alternating sense of rotation. An eddy pair is observed to extend from Cabo Lobos in each of the three years, suggesting that the eddies are topographically locked. The formation mechanism of the eddies remains unknown; however, we suspect the most likely mechanism includes baroclinic instabilities along the coast produced by interactions between coastally trapped waves, and local wind driven currents. INDEX TERMS: 4275 Oceanography: General: Remote sensing and electromagnetic processes (0689); 4520 Oceanography: Physical: Eddies and mesoscale processes; 4552 Oceanography: Physical: Ocean optics; 4279 Oceanography: General: Upwelling and convergences

\section{Introduction}

[2] The Gulf of California is a long $(1000 \mathrm{~km})$ and narrow $(150 \mathrm{~km})$ feature consisting of a series of basins (Figure 1). The northern gulf is shallow and separated from the deeper basins to the south by a sill and the midriff islands. The southern gulf includes the Guaymas basin in the north and a series of basins extending to the mouth. The gulf is nearly an ideal area for ocean color measurements. Mountains on the Baja California peninsula block the clouds and fog associated with the marine air over the Pacific. This allows the sky over the gulf to be nearly cloud free. The mountains on both sides of the gulf tend to polarize the winds so that they flow along the axis of the gulf. The winds then cause upwelling on one side of the gulf, which creates higher productivity along that coast. Furthermore, high tidal currents and possibly breaking internal waves on the sill between the northern and southern basins causes mixing and high productivity at the southern end of the islands. These regions of high productivity then provide biological material that can be used as tracers of the circulation within the gulf.

[3] Satellite measurements of sea surface temperature have been used to study the circulation in the Gulf of California [BadanDangon et al., 1985; Navarro-Olache, 1989; Paden et al., 1991; Lavin et al., 1997]. Sea surface temperature has also been used to provide an understanding of the biological production in the gulf [Gaxiola-Castro et al., 1999]. Here we use ocean color imagery from the Sea-viewing Wide Field-of-view Sensor (SeaWiFS) to observe the circulation within the Gulf of California, where regional surface heating during the summer may mask the circulation patterns that would be observed using sea surface temperature measurements [Paden et al., 1991]. The focus of our work is on the Guaymas basin and southern gulf. We extend the previous work that observed eddies in Guaymas basin in the spring and fall using sea surface temperature measurements [Badan-Dangon et al.,

Copyright 2002 by the American Geophysical Union. 0094-8276/02/2001GL014076\$05.00
1985; Navarro-Olache, 1989] by showing that the eddies are present through the summer as well. Features associated with the eddies can then be used to track the flow in the gulf [Svenjkovsky, 1988; Garcia and Robinson, 1989].

\section{Images}

[4] The SeaWiFS satellite became operational in October 1997. We have processed the October 1997 to May 2001 SeaWiFS ocean color images to level-2 chlorophyll maps using the SeaDAS software with the default settings of January 2001. Because we are not concerned with the magnitude of the chlorophyll concentrations we have not added color bars to the images. It suffices to say that blue and green colors represent lower concentrations and yellow and red high concentrations, black areas are land or clouds.

[5] The sea surface temperature (SST) images were obtained from the U.S. GLOBEC website maintained by Ted Strub at Oregon State University. The temperature range used is 25 to 29 degrees with blue colors being colder temperatures and red the warmest temperatures. The land, clouds, and water temperatures below 25 degrees are in black and brown.

\section{Results}

[6] Upwelling along the east coast of the gulf, and basin-wide eddies were found during August and September each year that SeaWiFS has been operating (Figure 2). In all three summers an eddy pair extended along a line from Cabo Lobos to south of Santa Rosalía with the anticyclonic eddy to the north and a cyclonic eddy to the south of the line (Figure 3). An anticyclonic eddy was observed west of Topolobampo each summer, but in 2000 it was displaced slightly southward towards La Paz. In 1999 and 2000 there is a cyclonic eddy evident northwest of Guaymas. In 1999 there is also clear evidence of a large anticyclonic meander at the mouth of the gulf. Combining the results from the three years suggests that there may be up to five eddies or meanders that fill the southern gulf each year (Figure 1); however, in some years not all eddies are evident, possibly because of a lack of gradients in the chlorophyll distribution. Eddies seen in the ocean color images are difficult to discern in the SST data (Figure 2).

[7] Several eddies were observed in the chlorophyll imagery collected between July and October in 1999. A five-day series of images collected between August 31 and September 4 is shown in Figure 3. An anticyclonic eddy in the Guaymas Basin had a core of high chlorophyll concentration that was approximately $70 \mathrm{~km}$ in diameter, moved westward across the gulf at $0.18 \mathrm{~m} \mathrm{~s}^{-1}$, and rotated once every 8 days with a maximum tangential velocity of $0.32 \mathrm{~m} \mathrm{~s}^{-1}$. A cyclonic eddy of the same size but with low chlorophyll values was observed south of the anticyclonic eddy. South of this eddy was another anticyclonic eddy (off Topolobampo) that was high in chlorophyll. Near the mouth of the gulf a squirt with high chlorophyll levels was observed to travel at $0.5 \mathrm{~m} \mathrm{~s}^{-1}$ across the gulf for two days and then it abruptly changed course and traveled up the gulf, defining another anticyclonic circulation. North of the midriff islands during August and September cyclonic circulation was observed. 


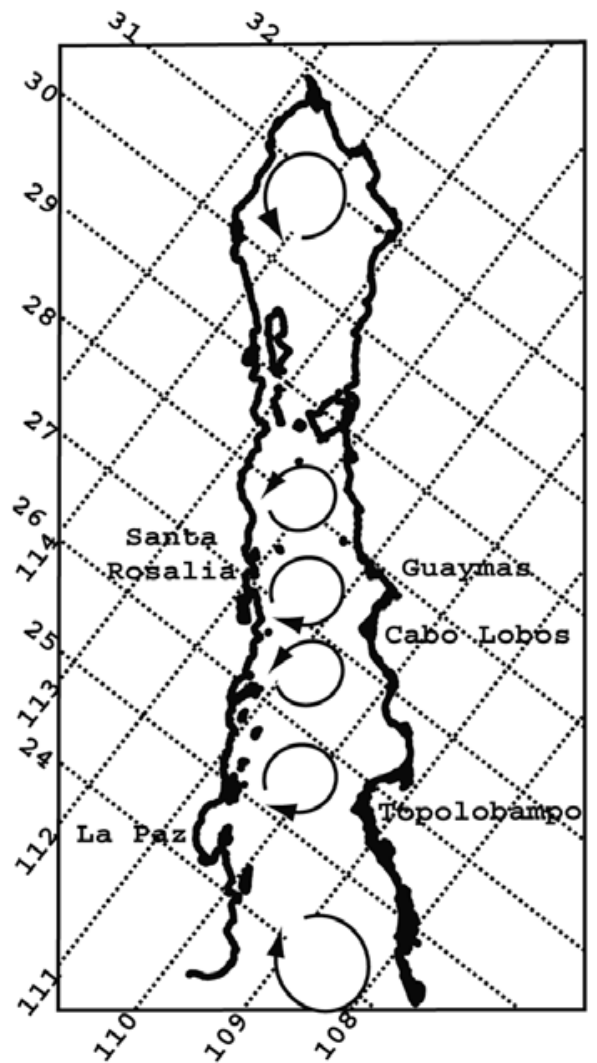

Figure 1. Map of the Gulf of California. The midriff islands $(29 \mathrm{~N})$ separate the shallow northern gulf from the deep southern gulf. The Guaymas basin extending from $27 \mathrm{~N}$ to the Midriff Islands and smaller basins exist towards the mouth of the gulf. The arrows represent the general circulation observed in the ocean color images.

[8] An important aspect in being able to determine circulation patterns by tracking biological features is that the motion must be large with respect to the growth and grazing of the phytoplankton. It is also important to have a gradient in the chlorophyll distribu-

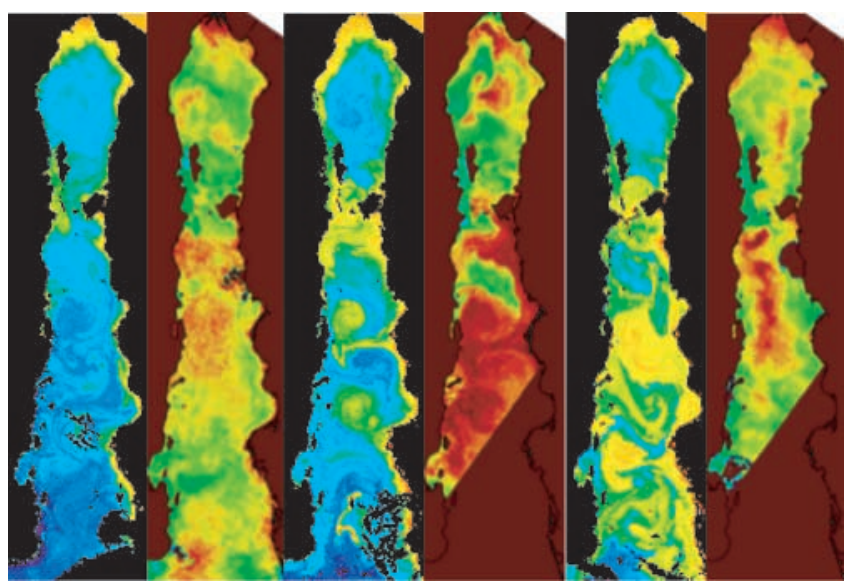

Figure 2. SeaWiFS chlorophyll (black land mask) and AVHRR SST (brown land mask) images from 30 August 1998, 4 September 1999, and 11 August 2000. In each image there is evidence of a pair of eddies extending between Cabo Lobos and south of Santa Rosalia.

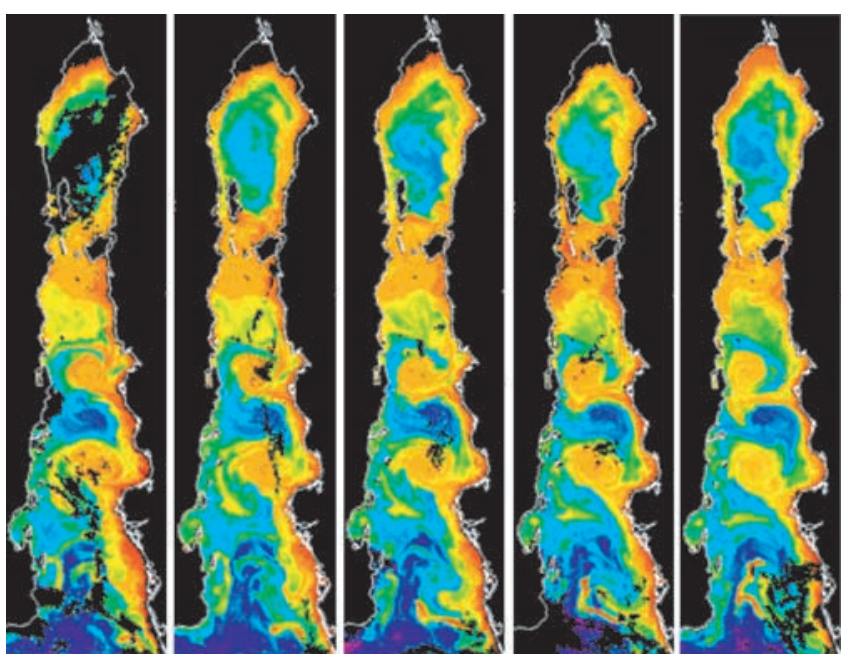

Figure 3. A series of SeaWiFS chlorophyll images from days 243 to 247 of 1999. Anticyclonic eddies with high chlorophyll concentrations are observed off Cabo Lobos and Topolobampo. A cyclonic eddy with low chlorophyll concentration is between the anticyclonic eddies. The cyclonic eddies are observed to be propagating towards the west. A narrow band of high chlorophyll is drawn around an anticyclonic meander near the mouth of the gulf.

tion. Our observations are based on being able to identify large features over a five-day period. The chlorophyll levels in the features did not remain constant over time; however, the features are clearly evident in each image and are displaced large enough distances that local growth and grazing are unlikely to produce the temporal changes observed.

\section{Discussion}

[9] Although the images presented here were collected in the late summer, upwelling, jets, eddies, and squirts are evident in the chlorophyll imagery through much of each year. In the late summer the eddy pair located south of Guaymas appears to be topographically locked. The higher chlorophyll values near Cabo Lobos appear to be advected into the northern, anticyclonic eddy and the cyclonic eddy appears to draw its water from the Baja California coast. The drawing of water from the coast can explain why the anticyclonic, downwelling favorable, eddy has high chlorophyll concentrations and the cyclonic, upwelling favorable, eddy has low chlorophyll concentrations. Examining several eddies observed over the three year period showed that the anticyclonic eddies were formed with chlorophyll-rich water from the eastern gulf and cyclonic eddies were formed from relatively clear water along the western gulf.

[10] The mechanism for forming the observed eddies is not clear. Interaction of wind driven currents with coastal trapped waves could induce separation of coastal currents or baroclinic instabilities. Baroclinic instability requires that the Rossby deformation radius $(\varepsilon=N H / f)$ has to be smaller than the horizontal scale of motion $(\varepsilon / L \leq O(1))$ [Pedlosky, 1987]. Close to the coast this instability condition is satisfied, with $H=200 \mathrm{~m}, N=8 \mathrm{e}-3 \mathrm{~s}^{-1}$, and $f=6.14 \mathrm{e}-5 \mathrm{~s}^{-1}$, the first baroclinic deformation radius is of the order of $30 \mathrm{~km}$, so that $\varepsilon / L \approx 0.42$. The forcing mechanisms for such waves may be local or remote, and may arise from atmospheric forcing such as wind or atmospheric pressure [for a review see Brink, 1991]. The wind driven currents may also interact with the coastline to form eddies or trigger the baroclinic instabilities.

[11] The high chlorophyll levels observed on the eastern boundary of the gulf suggest that upwelling favorable conditions exist 
during the late summer along the eastern and northern coast, which is consistent with winds derived from Quickscat measurements and the wind measurements on Isla Tortuga by Merrifield and Winant [1989] that show northerly wind bursts beginning in July. Rapid heating may remove the temperature signal of upwelling, which can explain why in 1999 the high chlorophyll concentrations were associated with warm waters. It may be that the high chlorophyll in the eastern gulf was due to an earlier upwelling event and that local heating had removed the associated temperature signal. The observed circulation in the northern Gulf of California is consistent with the analysis of Bray [1988], the hydrographic and drifter measurements of Lavin et al. [1997], and modeling results of Beier and Ripa [1999]. There are fewer studies of the circulation south of the midriff islands, with most of the work confined to the Guaymas basin. Bray [1988] shows a cyclonic eddy existing between Guaymas and Santa Rosalía in August. This is consistent with the cyclonic eddy seen in the northern portion of the Guaymas basin in 2000. Bray [1988] also shows an anticyclonic eddy at this location in October, which suggests that there are seasonal changes in the position of these eddies. Using SST imagery Badan-Dangon et al. [1985] describe a similar circulation pattern in the Guaymas Basin to that observed here, but for the months of March and April. SST imagery and hydrographic measurements were also used to observe the eddy pair off Cabo Lobos by Navarro-Olache [1989] during October to November 1985.

[12] These eddies, meanders, and jets are observed transporting phytoplankton into the deep waters of the gulf. During the summer this transport may be responsible for a large portion of the primary production that occurs over the deep water and thereby help maintain the high productivity of the region. It can also account for the rapid shifts in standing stocks and community structure that have been observed near Guaymas [Alvarez-Borrego and LaraLara, 1991].

\section{Conclusions}

[13] During the late summer a series of eddies approximately 70 to $100 \mathrm{~km}$ in diameter have been observed in each of the three years that SeaWiFS has been in operation. The length of the gulf south of the midriff islands appears to be filled with a series of eddies. The eddy set off Cabo Lobos reappears in the same region and has been seen in SST measurements made in the spring in fall, but are difficult to discern in the summertime images. The formation mechanism for the eddies remains unknown; however, baroclinic instabilities caused by interactions between the winddriven circulation, coastally trapped waves, and the topography and coastline are a likely source. To determine the exact manner of formation requires field or modeling studies and are not likely to be achieved from remote sensing alone.

[14] Because of intense surface heating during the summer the SST gradients tend to be related to spatial variations in the wind field [Paden et al., 1991] thereby decreasing the usefulness of SST measurements in determining the circulation of the region. The narrowness of the gulf limits the applicability of altimetry measurements that have sampling intervals that are wider than the size of features observed in the gulf. However, upwelling along the eastern and western boundaries of the gulf provides nutrients for biological growth that can be observed in ocean color measurements. The redistribution of the biological material into the central gulf can then be used to infer circulation in the region, which makes ocean color imagery a useful tool for studying circulation in the region.

[15] Acknowledgments. We thank Orbimage and the SeaWiFS Project (Code 970.2) and the Distributed Active Archive Center (Code 902) at the Goddard Space Flight Center for providing the SeaWiFS imagery. The high resolution images used were collected by the Monterey Bay Aquarium Research Institution. We thank Ted Strub, Ocean Imaging, and the US GLOBEC project for providing the sea surface temperature images. This research was supported by the Office of Naval Research Environmental Optics Program.

\section{References}

Alvarez-Borrego, S., and J. R. Lara-Lara, The physical environment and primary productivity of the Gulf of California, in The gulf and peninsular province of the Californias, edited by J. P. Dauphin and B. R. T. Simoneit, American Association of Petroleum Geologists, Tulsa, pp. 555-567, 1991.

Badan-Dangon, A., C. J. Koblinsky, and T. Baumgartner, Spring and summer in the Gulf of California, observations of surface thermal patterns, Oceanol. Acta., 8, 13-22, 1985.

Beier, E., and P. Ripa, Seasonal gyres in the northern Gulf of California, J. Phys. Oceanogr, 29, 305-311, 1999.

Bray, N. A., Thermohaline circulation in the Gulf of California, J. Geophys. Res., 93, 4993-5020, 1988.

Brink, K. H., Coastal-trapped waves and wind-driven currents over the continental shelf, Annu. Rev. Fluid Mech., 23, 389-412, 1991.

Garcia, C. A. E., and I. S. Robinson, Sea surface velocities in shallow seas extracted from sequential coastal zone color scanner satellite data, J. Geophys. Res., 94, 12,681-12,691, 1989.

Gaxiola-Castro, G., S. Alvarez-Borrego, M. F. Lavín, A. Zirino, and S. Nájera-Martínez, Spatial variability of the photosynthetic parameters and biomass of the Gulf of California phytoplankton, J. Plankt. Res., 21, $231-245,1999$.

Lavín, M. F., R. Durazo, E. Palacios, M. L. Argote, and L. Carrillo, Lagrangian observations of the circulation in the northern Gulf of California, J. Phys. Oceanogr., 27, 2298-2305, 1997.

Merrifield, M. A., and C. D. Winant, Shelf circulation in the Gulf of California: A description of the variability, J. Geophys. Res., 94, $18,133-18,160,1989$.

Navarro-Olache, Mesostructuras termohalinas en la parte central del Golfo de California, M. Sc. Thesis, CICESE, pp. 79, 1989.

Paden, C. A., M. R. Abbott, and C. D. Winant, Tidal and atmospheric forcing of the upper ocean in the Gulf of California 1. Sea surface temperature variability, J. Geophys. Res., 96, 18,337-18,359, 1991.

Pedlosky, J., Geophysical Fluid Dynamics, 2nd Edition. Springer-Verlag, New York, 710 pp., 1987.

Svenjkovsky, J., Surface flow estimation from advanced very high resolution radiometer and coastal zone color scanner satellite imagery: A verification study, J. Geophys. Res., 93, 6735-6743, 1988.

E. Boss, W. S. Pegau, and A. Martínez, College of Oceanic and Atmospheric Sciences, Oregon State University, 104 Ocean. Admin. Bldg., Corvallis, OR 97331, USA. (spegau@oce.orst.edu) 